\title{
ENTRE LAMPIÃO E DOM QUIXOTE: MOACYR SCLIAR A PARTIR DE "MÊS DE CÃES DANADOS"
}

\section{BETWEEN LAMPIÃO AND DON QUIXOTE: MOACYR SCLIAR BASED ON "MÊS DE CÃES DANADOS"}

Ana Cecilia Agua de Melo*

\section{Resumo}

Este artigo se concentra em Mês de cães danados (1978), novela em que Moacyr Scliar põe em cena a Campanha da Legalidade liderada pelo então governador do Rio Grande do Sul, Leonel Brizola, depois da renúncia do presidente Jânio Quadros, em 1961. Discute-se como o narrador-protagonista marca o aparecimento da primeira pessoa picaresca que persistiria até o fim da carreira de Scliar, fazendo-se presente nos panoramas históricos de Sonhos tropicais, A majestade do Xingu, entre várias outras obras do autor. Abrangendo a estreia do escritor gaúcho na chamada fícção para jovens, este artigo mostra como o pendor informativo do narrador vai ganhando espaço, em detrimento da fragmentação observada em Mês de cães danados.

Palavras-chave: Moacyr Scliar, Ficção Brasileira, Século XX.

\begin{abstract}
* Doutora em Teoria e História Literária pelo IEL/Unicamp.
\end{abstract}


Cad. Líng. Lit. Hebr., n. 15, p. 93-109, 2017

This article focuses on Mês de cães danados (The Month of Damned Dogs) (1978), a novel in which Moacyr Scliar put on scene the Campanha da Legalidade (Legality Campaign) led by the then governor of the state of Rio Grande do Sul, Leonel Brizola, after president Jânio Quadros resigned in 1961. The discussion is about how the narrator-protagonist marks the emergence of the picaresque first person that would persist until the end of Scliar's career, making itself present in the historical panoramas of Sonhos tropicais (Tropical Dreams) and $A$ majestade do Xingu (The Lord of the Xingu), among several of his other works. Covering the gaucho writer's debut in the so-called young adult literature, this article shows how the narrator's tendency to be informative gains ground to the detriment of the fragmentation observed in Mês de cães danados.

Keywords: Moacyr Scliar, Brazilian Fiction, Twentieth Century. 
Carlos Vogt se sentiu estimulado a fazer um balanço da produção de Moacyr Scliar já em 1978, mesmo sabendo que acabara de aparecer um livro que poderia estar anunciando novos caminhos na ficção do escritor gaúcho (VOGT, 2012, p. 71-80). Com efeito, Mês de cães danados, vencedor, ainda na condição de inédito, do Prêmio Brasília em 1977, foi o primeiro livro de ficção longa em que Scliar ensaiou alguns passos para além do seu até então universo de eleição, o dos imigrantes judeus do bairro do Bom Fim, em Porto Alegre (SCLIAR, 1996).

Se se afastava dos domínios pelos quais já se tornara conhecido entre os nossos ficcionistas contemporâneos, Scliar continuava explorando a matéria da experiência vivida. O subtítulo "Uma aventura nos tempos da Legalidade" deixa claro que está em questão o movimento liderado por Leonel Brizola, então governador do Rio Grande do Sul, na crise que se seguiu à renúncia do presidente Jânio Quadros, em 1961. Quem conhece a autobiografia que Scliar foi cristalizando em depoimentos e textos dispersos sabe que os dias em que esteve em jogo a posse de João Goulart são um episódio importante na vida do autor, então jovem estudante de medicina envolvido com política estudantil.

Mês de cães danados é um ponto de referência entre os livros de Scliar não só pelo motivo que acabei de lembrar, a expansão das fronteiras para além do Bom Fim. Numa curiosa consonância, o livro faz alusão a uma figura em processo de se projetar da política gaúcha para a linha de frente das esquerdas brasileiras - em 1962 Brizola já era deputado federal pelo antigo estado da Guanabara - quando seu autor estava prestes a experimentar a mão numa matéria mais amplamente brasileira, menos gaúcha. Não só isso. É em Mês que aparece a primeira pessoa de raiz picaresca que viria a moldar as ficções longas até o fim de sua carreira. Essa primeira pessoa funcionaria como veículo dos ágeis panoramas históricos que deram vazão à veia enciclopédica de Scliar, também muito presente nas crônicas. Basta 
Cad. Líng. Lit. Hebr., n. 15, p. 93-109, 2017

lembrar de A estranha nação de Rafael Mendes, Cenas da vida minúscula, Sonhos tropicais, A majestade do Xingu e Eu vos abraço, milhões, o último da série.

Mas em Mês o processo ainda está se esboçando. Trata-se da história recente - o momento flagrado significa um recuo de dezesseis anos em relação à data de aparecimento do livro - e o enciclopedismo de certa forma já existe, mas cumpre função diferente daquela que ganharia nos anos por vir. Além do mais, embora a aventura narrada ocorra "nos tempos da Legalidade", seus episódios, pelo menos num plano imediato, pouco se relacionam com a crise política em si. Mário Picucha, o narrador-protagonista, anuncia a seu interlocutor que “de agosto de 1961 posso te contar tudo". Sim, ele pode, mas o "agosto de 1961" dele mais colide do que se relaciona com os graves eventos nacionais. Tendo vivido, por casualidade, um processo pessoal de derrocada no ano e no mês fatídicos, e em Porto Alegre, Mário Picucha se torna a memória da Legalidade. Não fosse a coincidência, ele seria uma fonte pouco confiável, já que tropeçou em acontecimentos de cuja dimensão tinha pouca (ou nenhuma) ideia.

Mas quem é esse narrador? "Mário Picucha” é a alcunha autoatribuída de uma espécie de mendigo que passa seus dias num trecho da calçada da rua General Câmara (antiga rua da Ladeira), no centro histórico da capital gaúcha. Com a mobilidade comprometida por uma fratura exposta - com que se concluiu, para ele, o frenesi daqueles dias - e protegido pela couraça de um velho e imundo poncho, Mário oferece a um interlocutor (ao qual ele atribui, por inferência, a alcunha de "Paulista"), em troca de algumas moedas, sua história de agosto de 1961, dividindo sua fala em "capítulos" correspondentes, cada um, a um dia entre 18 e 31 daquele mês.

À parte a condição degradada e o fato de sua história pregressa compor um romance de deformação, o narrador ostenta um peculiar traço de erudição escolar, além de que não escapa 
de seus olhos nenhum pedaço de jornal e revista dos que se acumulam em volta dele na calçada. Mais importante, entre as poucas atividades de seu cotidiano estão penosas idas periódicas (ele tem que se arrastar por causa da perna doente) até a Biblioteca Municipal, onde consulta, nos arquivos do jornal Correio do Povo, notícias referentes a agosto de 1961.

Dessa maneira, a fala de Picucha é, por assim dizer, perfurada por fragmentos qualificados (o noticiário político) e desqualificados (miscelâneas como anúncios de remédio) de edições antigas do jornal. Esses fragmentos estão enxertados no discurso do narrador segundo a descontinuidade e a desordem das lembranças do jovem Mário Picucha, que recebia o Correio do Povo todas as manhãs em seu apartamento quando estudante.

Que estranho porta-voz da memória coletiva! Mau leitor, marginalizado, sem profissão, Picucha se improvisa em fonte sobre a Campanha da Legalidade muito simplesmente porque chegou ao fim da picada justo nos dias em que Brizola se entrincheirou no Palácio Piratini. Ele parece saber disso e não se leva a sério, se apresentando ao suposto Paulista como um guia turístico gaiato, um entertainer.

No ano do lançamento de Mês, numa conversa de críticos que debatiam com Davi Arrigucci Jr. algumas hipóteses deste sobre obras de ficção que iam aparecendo e tentavam dar conta de nossa história recentíssima, Flávio Aguiar salientou a presença do jornal em Mês, lembrando que a Legalidade é contada, sobretudo, graças à colagem das manchetes, o que lhe parece insuficiente. Em suas palavras, esta seria uma "representação pobre" do momento que a narrativa teria pretendido abarcar (ARRIGUCCI et al., 2012, p. 39).

Decorridos quase quarenta anos, por que não tentar avaliar o problema por outro ângulo? Digamos que o livro cujo título e subtítulo jogam o foco sobre um determinado momento da história recente do país na verdade sonega o assunto prometido, avançando no ritmo das historietas, devaneios, piadas e casos que embalam um percurso de (de)formação 
Cad. Líng. Lit. Hebr., n. 15, p. 93-109, 2017

irrisório e precocemente interrompido. Assim, a dimensão "séria" da grande política está lá, mas submetida ao discurso rebaixado desse narrador que, por acidente, foi uma testemunha desatenta. $\mathrm{O}$ resultado poderá ter posto em questão a viabilidade de representar, como queria Flávio Aguiar, os eventos históricos.

O narrador à margem na Porto Alegre de meados dos anos 1970 tem atrás de si uma vida malsinada que se alterna entre três espaços-tempos: uma estância (para ele) imaginária; a casa da tia em Pelotas, onde amargou desde criança uma espécie de exílio; e a cidade de Porto Alegre no começo dos anos 1960, onde se instala a pretexto de cursar a faculdade de direito. O nó da vida de Mário Picucha é a ambiguidade de sua condição: é filho de estancieiro, mas ilegítimo, gerado no ventre de uma mulher pobre que o pai mantinha. Ao descobrir que tinha sido contaminado pela gonorreia, o patriarca se desembaraçara da mulher e degredara o filho de ambos na casa da irmã solteirona em Pelotas, sustentando-o à distância. Nem bem aceito, nem bem renegado, Mário Picucha simbolicamente veio de uma fonte envenenada, visto que o pai anos depois viria a morrer das consequências da infecção. Na periferia da órbita do proprietário de terras, o menino se fecha em devaneios (confinado no exíguo quintal da casa da tia), idealizando uma vida idílica na propriedade rural onde nunca pôs os pés e apagando a mãe.

Histórias de um quixote degradado são o que Mário Picucha tem para entreter o Paulista. Dono de uma imaginação delirante calcada nos estereótipos ligados ao gaúcho, sua fala mistura as fantasias do menino que dava voltas no quintal sonhando com cavalgadas nos pampas com a trajetória errática (e também fora de sintonia com a realidade) do rapaz que tentou fincar os pés na capital. A narrativa revive a degringolada de uma personagem que, repetindo as bravatas de uma classe que é e não é a sua, perambula pela cidade convulsionada 
pelo movimento liderado por Brizola desenhando uma espécie de versão apequenada, irrisória dos eventos com que tromba.

O desempenho da masculinidade, no nível mais estreitamente físico, é a base do comportamento de Mário Picucha. Encenando a nostalgia do gaúcho da Campanha, a cavalo, dedicado à lida do pastoreio, esse narrador falsifica sua presença numa cena tipificada, vazia de experiência: "Sou de novo guri, paulista, na fazenda de meu pai. Olha, lá vem ele, montado em seu cavalo, a peonada galopando atrás. Vão cercar a boiada. Vão separar as reses que serão depois vendidas. E abatidas. E carneadas. E assadas, e comidas. Pronto: passou a minha infância" (SCLIAR, 1996, p. 11). No tempo de recém-chegado a Porto Alegre, desloca para a cidade grande sua versão do homem rijo dos pampas, afirma seus laços sanguíneos com a criação de gado devorando carne e, no mais, se dedica a circular com um carrão, frequentar bordéis e enfim conquistar (à custa do dinheiro do pai) um apartamento onde pode manter a amante. Na plenitude da macheza, enfrenta três brigadianos que chegam numa radiopatrulha para flagrar uma farra automobilística com prostitutas. O Picucha narrador, imundo e capenga, evoca seu corpo jovem que cintila diante dos policiais.

No tempo de Pelotas, a tia, solitária, enclausurada, foi a mestra dos anos de desaprendizagem. Inoculou no menino o imaginário das novelas de cavalaria, apresentou-lhe a espada de um suposto antepassado guerreiro, lhe deu aulas de tiro no quintal. Do cavaleiro Rolando, da espada com o "nome ilustre" (qual?) gravado no copo, do grande revólver que aprendeu a manusear e depois ganhou de presente para debutar no grande mundo, Picucha extrai o pênis em que se fixa e que exibe, orgulhoso, para os brigadianos.

Assim reduzidos, drasticamente, os atributos do guerreiro, o jovem Mário Picucha encerra sua carreira porto-alegrense numa espécie de demanda da potência perdida, simultânea à Campanha da Legalidade. Como, nessa altura, o pai está padecendo da uremia 
Cad. Líng. Lit. Hebr., n. 15, p. 93-109, 2017

que o levará ao túmulo, o ímpeto viril, além de irrisório, está fadado a gorar, se entendemos que os males do pai prenunciam os do filho. Como o peixe morre pela boca, ambos morrem pelo falo, embora a morte de Picucha seja apenas simbólica.

Imagens insólitas aludem ao destino truncado do narrador-protagonista. Um momento privilegiado é a menção ao "curioso pandemônio" do quintal de Pelotas: "A cabeça - meiacabeça - de uma boneca de porcelana. As rodas, quebradas, de uma charrete. A armação de uma sombrinha. A estatueta do guerreiro. As presas da cobra. A pata do cão. A escarradeira. O olho" (SCLIAR, 1996, p. 61). Avesso da limpeza maníaca da casa, o quintal entulhado sugere decomposição - assim como a matéria orgânica, os objetos se decompõem em fragmentos desemparelhados -, confusão, sinistro.

Já indiquei que a crise pessoal de Mário Picucha corre em paralelo à crise política de agosto de 1961. Se, à primeira vista, as duas estão desconectadas (a não ser pelo fato de que Picucha, assumindo o lugar de classe do pai estancieiro, se diz afrontado pelo "pulha" Brizola), é cabível entender que a degringolada do estudante alude aos eventos públicos cujo fluxo narrativo é perturbado pelo entulho mental do historiador improvisado. O fato é que nosso guerreiro protagoniza um enredo de pornochanchada cujo ápice - uma clamorosa falha sexual com a amante mais velha, desquitada e antiga dona do Cadillac rabo-de-peixe com que ele se exibe em Porto Alegre - se dá na véspera da renúncia de Jânio. A questão é: o que a pornochanchada diz (ou não diz) da Campanha da Legalidade?

Quis o acaso que agosto entrasse para o anedotário e até para a mística política brasileira como o mês do suicídio de Getúlio Vargas e da renúncia de Jânio Quadros. Os dois eventos têm elos mais profundos que a coincidência das datas, visto que o ocupante do Palácio do Piratini em 1961 se fez herdeiro do cabeça da Revolução de 30. Nas palavras de Jorge Ferreira, a carta-testamento que Vargas deixou ao se suicidar, em 24 de agosto de 1954, 
é o "texto fundador" do trabalhismo de Brizola, cujo discurso reivindicava o legado de um Vargas martirizado (FERREIRA, 2016, p. 40).

Quando Jânio renunciou, em 25 de agosto de 1961, e os ministros militares intentaram impedir a posse de João Goulart, vice-presidente naquele momento em viagem à China, Brizola, num ato de inegável bravura e com carisma ímpar, arregimentou, da sede do governo do Rio Grande, um movimento nacional, ganhando a adesão do comandante do III Exército, o general Machado Lopes, o que frustrou os planos dos golpistas. É célebre o discurso que o governador proferiu, através das ondas de rádio da Rede da Legalidade, em 28 de agosto.

Incorporando a "tradição guerreira do sul", onde a política é experimentada como uma prática "viril, a ser enfrentada a ferro e fogo" (FREIRE; FERREIRA, 2016, p. 11, 18), o futuro idealizador dos Grupos dos Onze usou da oratória para fazer do Palácio do Piratini "cidadela heroica", sem mãos a medir na grandiloquência. A frase "A morte é melhor do que a vida sem honra, sem dignidade e sem glória", dita por um Brizola armado e convocando às armas a população, aponta para a dimensão teatral séria da Campanha da Legalidade.

Empunhando o revólver presenteado pela tia, com o qual se limita a dar espalhafatosos mas inócuos tiros nos globos de luz da sala de aula da faculdade, Mário Picucha pode ser lido como um deslocamento, apequenado e com sinal ideológico invertido, da figura de Brizola. Sempre no registro irrisório, Picucha conta ao Paulista que "mostrou sua vocação para a luta política" num episódio juvenil de troca de bilhetinhos com a professora de francês. Enfim, a macheza estreita, em que "guerreiro" vira apelido do pênis, e o frenesi esvaziado de um acadêmico de direito alucinado, mas chinfrim, vão para o centro do palco, tomando o lugar de Brizola.

Nesse nível, teríamos a Campanha da Legalidade representada por alusão. Porém, o conjunto resulta numa abordagem um pouco menos enviesada do que o procedimento que 
Cad. Líng. Lit. Hebr., n. 15, p. 93-109, 2017

acabei de descrever sugere. Primeiro, muitos fragmentos do Correio do Povo ostentam coisas como "Cestas de Natal Amaral”, mas outros são extraídos do noticiário político, isto é, introduzem menções diretas aos eventos. Além disso, a correria sem rumo que se segue à brochada, simultânea à eclosão da crise nacional, é um artifício para que Mário Picucha circule pelas ruas de Porto Alegre e absorva, ainda que de raspão, o que acontece. Assim, na saída de um teatro, ele e a amante Júlia entreouvem "o porteiro dizer a um brigadiano que Jânio tinha renunciado" (SCLIAR, 1996, p. 129). E ainda, o narrador se lembra de concluir a história, para não deixar o Paulista ignorante do desfecho da crise: "Depois, o Congresso apoiou a emenda parlamentarista. João Goulart viajou para Brasília. Os ministros militares garantiram sua posse" (SCLIAR, 1996, p. 184).

Em síntese, teríamos o seguinte: no nível em que as tropelias de Mário Picucha aludem aos eventos políticos, Mês de cães danados contaria menos a história da Campanha da Legalidade do que uma variação daquela que já vinha sendo contada desde $A$ guerra no Bom Fim: se, nas palavras de Berta Waldman, a novela ${ }^{1}$ de estreia, além de Os deuses de Raquel, $O$ ciclo das águas e outras, conta "o aburguesamento da segunda geração de judeus, a integração a um estilo de vida brasileiro", Mês, muito proximamente, se ocupa das aspirações diluídas de uma classe média que tratava de se adaptar ao ritmo de nossa modernização conservadora (WALDMAN, 2003, p. xxix). A carreira juvenil calcada no usufruto vazio de um status social manco e a consciência de Mário Picucha de que pode tirar proveito de um mercado de turismo já instalado apontam para o fôlego curto do arrojo idealista encarnado na figura de Leonel Brizola e a posse de João Goulart é contada da perspectiva do que veio depois, a liquidação do programa das esquerdas. Em contrapartida, o guia turístico gaiato pode ser lido como um truque para transmitir o conteúdo visado, a Campanha da Legalidade. Numa medida, o ponto

\footnotetext{
1 Embora eu prefira falar em "ficção longa", lembro que Scliar gostava do termo "novela", achando que "romance" soava "muito pretensioso, ao menos para o que faço" (SCLIAR, 2008, p. 184).
} 
de vista apequenado de Mário Picucha critica o plano dos grandes eventos; noutra, ele seria um expediente didático para narrá-los de modo agradável.

Na conversa com Arrigucci, essa ambiguidade dos resultados de Scliar já é constatada e discutida como sintoma de um problema mais amplo, qual seja, a dupla face - criativa e mercadológica - do impulso que a ficção brasileira ganhava nos anos de 1970. A postura de cada escritor diante do ofício, bem como o grau de elaboração literária, variava, é claro. Moacyr Scliar já se mostrava inclinado a aceitar uma parceria duradoura com o mercado editorial que atravessava novo período de expansão, o que não teria como não se refletir nos contornos de sua ficção.

Em Mês de cães danados, o pendor rocambolesco da mente do contador de histórias Mário Picucha se transfere para o enredo, o que faz jus à "aventura" anunciada no subtítulo. A certa altura, Mário identifica o irmão Artêmio ao lado de Brizola. O leitor pode ter a impressão de que se trata de um surto alucinatório da personagem, mas não, Artêmio teria rompido com a família na estância e se juntado ao grupo do governador. Em seu lugar imaginário de membro do clã de estancieiros, Picucha se sente imbuído da missão de dissuadir o irmão dessa desastrosa mudança de lado. O rocambolesco de tal enredo se junta às historietas que desviam a atenção da história anunciada e sonegada, mas também funciona como maneira de ilustrar, com ligeireza, o conflito de classes.

Esses contornos não tardariam a ficar mais nítidos. Uma breve novela como que abriu por conta própria a trilha da literatura para jovens que o autor palmilharia - não exclusivamente - até o fim da vida. Publicada em 1981 como ficção para adultos, Cavalos e obeliscos encontrou um público que quase duas décadas depois justificou uma nova edição numa coleção voltada a leitores adolescentes. Ainda estão em cena o Rio Grande do Sul e 
Cad. Líng. Lit. Hebr., n. 15, p. 93-109, 2017

suas histórias, mas o romance de deformação dá espaço a um pequeno romance da desilusão em tom agridoce, com a bênção de Erico Verissimo.

A novela se abre em plena sala de aula, onde uma professora de português pede ao menino Ernesto que identifique o texto que ela lê para a classe. O garoto hesita, é distraído, mas acaba respondendo que se trata do conto "Os devaneios do general", de Verissimo. Muito bem. E é como uma glosa ao mote do conto que Cavalos e obeliscos se desenrola, contrapondo avô e neto, o fabulário gaúcho e o ramerrão do presente. Se em Mês de cães danados o narrador negocia barato com o "Paulista", na novelinha de 1981 o garoto ingênuo de Potreiros, no interior do Rio Grande, tem nas histórias que escreve sobre o avô, outro Picucha, o passaporte para o Rio de Janeiro, onde um improvável produtor de tevê busca "um herói regional, por exemplo; e picaresco, algo entre Lampião e Dom Quixote” para criar uma telenovela (SCLIAR, 2001, p. 11). A narração é em terceira pessoa e, embora a breve temporada carioca de Ernesto seja um rito de iniciação em certa medida análogo ao de Mário Picucha em Porto Alegre, trata-se de uma descida aos infernos bem menos catastrófica e, além de tudo, reversível. No fim, a personagem reemerge - sem fraturas, literais ou metafóricas, e virgem como era ao princípio, diga-se - para voltar ao caminho traçado em Potreiros.

De uma tacada só, Cavalos e obeliscos junta a instituição escolar, a referência ao escritor consagrado, o repertório de histórias gaúchas, sua circulação no centro do país e a viabilidade do herói picaresco dentro da indústria cultural. Claro que o aspirante a escritor Ernesto, exatamente como o contador de histórias Mário Picucha, é uma projeção do ficcionista em vias de se profissionalizar, de ter "casa montada", na expressão de Autran Dourado. Tal projeção, no caso de Mês, foi descrita por Flávio Aguiar como “consciência da imediatez", de "um certo apressamento na produção do romance" (ARRIGUCCI et al., 2012, 
p. 41). O esquema "alguns centavos na latinha, e lá vai a história" trairia o improviso, a disponibilidade para um mercado editorial onde a agilidade é vista como uma boa parceira do talento. Já o menino Ernesto, chamado ao Rio de Janeiro só para ser enrolado e depois deixado a ver navios pelo produtor de tevê, pode ser uma imagem cândida do letrado tanto seduzido quanto irremediavelmente "puro" e alheio às engrenagens do mercado da cultura.

Mas falta especificar melhor qual o mote de que Scliar parte para escrever Cavalos $e$ obeliscos. Em "Os devaneios do general", temos um bisavô, o chimango Chicuta Campolargo, já decrépito, tendo de passar seus últimos dias suportando o democratismo que tomou conta de sua velha Jacarecanga, sem falar no bisneto, um provável futuro bacharel em direito, quem sabe socialista como o pai. Sua maior nostalgia são as cabeças que fez rolar na revolta de 1893. Esse o mote. Na novela de 1981, um idealizado avô maragato, rebelde de 1923, cai do pedestal diante do neto Ernesto, que, findo o rito de passagem no estilo ilusões perdidas, segue a vida até se tornar advogado. $\mathrm{O}$ arco temporal se estende. $\mathrm{O}$ ano da aventura de Ernesto no Rio é 1971; a personagem do avô remete à revolução de 1923; o conto de Erico Verissimo, explicitamente citado, introduz a Revolução Federalista; ao fim, Ernesto é flagrado nos primeiros passos da vida adulta, tentado pela carreira política no "clima de abertura no país”. Nos dois textos, os autocratas, sejam eles chimangos, maragatos ou milicos anticomunistas, perdem terreno para a normalidade democrática que se esboça. Mas, enquanto Verissimo espezinha o velho general degolador, submetendo-o à altivez vingativa de um enfermeiro negro, o coronel Picucha de Scliar resulta num malandro malfadado e digno de ternura. Um avô que conta histórias ao neto.

Apesar dos marcos temporais explícitos, Scliar parece menos interessado em pôr em discussão os eventos históricos que em lançar mão deles como, justamente, motes glosáveis pelo prazer de inventar e narrar. Se Ernesto sai de Potreiros com as histórias de um avô- 
Cad. Líng. Lit. Hebr., n. 15, p. 93-109, 2017

Munchausen debaixo do braço e encontra o Picucha de carne e osso, na forma de um velho vigarista, o saldo é o poder da fantasia, que faz o jovem advogado sonhar com o episódio do cavalo amarrado no obelisco, apesar de não ter mais o ardor para escrever. De resto, numa glosa ao mote de Mês de cães danados, em que o narrador é um arremedo de gaúcho guerreiro no centro de Porto Alegre, Picucha, ao bolar um estratagema para ajudar o neto a cair fora do hotel sem pagar a conta, munindo-se de um pau de cortinado para enfim morrer num inglório atropelamento, duplica em tom irrisório os atos de bravura cantados em torno da sua pessoa.

Até Eu vos abraço, milhões, de 2010, a ficção de Moacyr Scliar persistiria nessas linhas cruzadas entre curta e longa duração, banalidade cotidiana e excepcionalidade, gente comum e grandes vultos, de modo que, embora Berta Waldman identifique "duas tipologias", as narrativas da "micro-história familiar" e aquelas dos "grandes painéis históricos", prefiro destacar que desde A guerra no Bom Fim a grande história esteve à espreita no miudinho da vida no Bom Fim. A diferença é que, nas primeiras novelas, o "micro" é que ditava o ritmo da narração.

Nas ficções longas que se sucederam a partir de Mês de cães danados, Moacyr Scliar pode ter se exercitado num desdobramento do que Walnice Nogueira Galvão identificou como o "novo biografismo", exemplificado pelo best-seller Olga, de Fernando Morais. Ainda que nutridas de toda uma bibliografia acadêmica, tais obras são em geral escritas por jornalistas, em linguagem acessível, e se dirigem a um público bastante amplo. Se o pontapé inicial dessa tendência que tomou corpo nos anos de 1990 foi a revisitação da galeria de personagens das esquerdas derrotadas em 1964, logo apareceram livros voltados aos mais diferentes períodos da história do Brasil (GALVÃO, 2005). 
Em Mês de cães danados, cujo centro é um evento pré-1964, a grande personagem que poderia estar em questão, Leonel Brizola, é encoberta pelo espalhafato do personagemnarrador apequenado. Já em A majestade do Xingu (1997), embora a narração esteja a cargo de um homem que viveu uma vida pequena, sua fala nos dá um Noel Nutels (outra figura emblemática das esquerdas brasileiras) de corpo inteiro. Desse modo, dá para dizer que a biblioteca até onde Mário Picucha tem o hábito de se arrastar vai impondo sua presença nas ficções que vieram depois, ficando, por assim dizer, mais ao alcance do narrador, que se deixa permear pelos conteúdos da historiografia, oferecendo uma história "mais bem contada", quer dizer, mais franca em sua intenção de esclarecer o leitor. Daí o parentesco com o "novo biografismo".

Por último, uma palavra à margem da questão lançada por Berta Waldman: "Seriam mais judaicos os textos de Moacyr Scliar que tematizam a condição dos judeus em Porto Alegre do que outros que passam ao largo dessa temática?” (WALDMAN, 2003, p. xxi). Uma edição de Os deuses de Raquel chega a apresentar Scliar como "um dos maiores romancistas especialistas em temática judaica do mundo”. Sejamos razoáveis, não há romancista "especialista" em temática alguma. Scliar nasceu no bairro do Bom Fim, como filho de um casal de judeus imigrados, e essa experiência esteve na origem de sua atividade de ficcionista. O Bom Fim foi um começo. Mas o hibridismo que fere a Esther sereia de $O$ ciclo das águas e o Guedali de $O$ centauro no jardim, personagens marcadas pela condição judaica, também está em Mário Picucha, condenado a viver no meio a meio dos meios-irmãos, ele que é meio filho de proprietário e meio filho do povo anônimo. Entregue a uma correria que simula ter um alvo, Picucha sofre de uma mobilidade paradoxal semelhante à que Berta Waldman observa nas personagens de que se ocupa. Tais recorrências, que podem traduzir o que se 
Cad. Líng. Lit. Hebr., n. 15, p. 93-109, 2017

chamaria de visão de mundo do autor, relativizam a circunscrição de Moacyr Scliar como escritor debruçado sobre os imigrantes de origem judaica. 


\section{Bibliografia}

ARRIGUCCI JUNIOR, D.; VOGT, C.; AGUIAR, F.; WISNIK, L. T.; LAFETÁ, J. L. Jornal, realismo, alegoria (romance brasileiro recente). Remate de Males, Campinas, v. 1, p. 11-50, 2012.

FERREIRA, J. Nacionalismo, democracia e reformas: as ideias políticas de Leonel Brizola (1961-1964). In: FREIRE, A.; FERREIRA, J. A razão indignada. Leonel Brizola em dois tempos (1961-1964 e 1979-2004). Rio de Janeiro: Civilização Brasileira, 2016. p. 23-51.

FREIRE, A.; FERREIRA, J. Apresentação. In: FREIRE, A.; FERREIRA, J. A razão indignada. Leonel Brizola em dois tempos (1961-1964 e 1979-2004). Rio de Janeiro: Civilização Brasileira, 2016. p. 17-20.

GALVÃo, W. N. As musas sob assédio. Literatura e indústria cultural no Brasil. São Paulo: Senac, 2005.

SCLIAR, M. Cavalos e obeliscos. São Paulo: Ática, 2001. . Mês de cães danados. Uma aventura nos tempos da "Legalidade". 4. ed. Porto Alegre: L\&PM, 1996.

. Depoimento. In: VAN STEEN, E. (Org.). Viver e escrever 3. 2. ed. Porto Alegre: L\&PM, 2008. p. 179-187.

VOGT, C. A solidão dos símbolos (uma leitura da obra de Moacyr Scliar). Remate de Males, Campinas, v. 1, p. 71-80, 2012.

WALDMAN, B. Entre passos e rastros. Presença judaica na literatura brasileira contemporânea. São Paulo: Perspectiva, 2003. 